\title{
Synthesis of cross-conjugated trienes by rhodium- catalyzed dimerization of monosubstituted allenes
}

Tomoya Miura, Tsuneaki Biyajima, Takeharu Toyoshima and Masahiro Murakami*

Full Research Paper
Address:
Department of Synthetic Chemistry and Biological Chemistry, Kyoto
University, Katsura, Kyoto 615-8510, Japan
Email:
Tomoya Miura - tmiura@sbchem.kyoto-u.ac.jp; Masahiro Murakami* -
murakami@sbchem.kyoto-u.ac.jp
${ }^{*}$ Corresponding author
Keywords:
allene; cross-conjugated triene; dimerization; rhodium; stereoselective
Beilstein J. Org. Chem. 2011, 7, 578-581.

doi:10.3762/bjoc. 7.67

Received: 25 January 2011

Accepted: 30 March 2011

Published: 09 May 2011

This article is part of the Thematic Series "Allene chemistry".

Guest Editor: K. M. Brummond

(C) 2011 Miura et al; licensee Beilstein-Institut. License and terms: see end of document.

\begin{abstract}
A rhodium(I)/dppe catalyst promoted dimerization of monosubstituted allenes in a stereoselective manner to give cross-conjugated trienes, which are different from those obtained by a palladium catalyst.
\end{abstract}

\section{Introduction}

Cross-conjugated trienes, known as [3]dendralenes [1], are attractive synthetic precursors used for consecutive double $[4+2]$ cycloaddition reactions [2-4] to provide a rapid access to polycyclic carbon frameworks. Thus, a number of methods for the preparation of the parent 3-methylenepenta-1,4-diene [5] and its substituted derivatives [6-17] has been developed. Among these, transition-metal-catalyzed dimerization of allenes presents a unique entry to substituted cross-conjugated trienes. For example, a nickel( $(0) /$ triphenylphosphine complex catalyzes a dimerization reaction of 3-methylbuta-1,2-diene to afford 2,5dimethyl-3,4-bismethylenehex-1-ene [18,19]. The nickelcatalyzed reaction, however, leads to a complex mixture of products when monosubstituted allenes such as penta-1,2-diene and 1-phenylpropa-1,2-diene are employed [20]. On the other hand, a palladium-catalyzed dimerization reaction of monosubstituted allenes produces substituted cross-conjugated trienes 2 in high yield (Scheme 1) [21]. We report here that dimerization of monosubstituted allenes is also catalyzed by a rhodium(I)/ dppe complex to form cross-conjugated trienes $\mathbf{3}$, which are different from those obtained with the palladium catalyst.

\section{Results and Discussion}

We initiated our study using undeca-1,2-diene (1a) as the model substrate and a rhodium(I) complex as the catalyst (Table 1). When 1a was treated with a catalytic amount of $[\mathrm{RhCl}(\operatorname{cod})]_{2}$ ( $2.5 \mathrm{~mol} \%, \operatorname{cod}=$ cycloocta-1,5-diene) in toluene at $130{ }^{\circ} \mathrm{C}$ for $12 \mathrm{~h}, \mathbf{2 a}$ was formed in $40 \%$ NMR yield along with another minor dimerized product (13\% NMR yield) and unidentified 


$$
\text { cat. Rh(I)/L }
$$

Scheme 1: A new entry to substituted cross-conjugated trienes.

compounds (Table 1, entry 1). The structure of the minor dimerized product was determined to be $(E)$-10,11-dimethyleneicos8-ene (3a) by ${ }^{1} \mathrm{H}$ and ${ }^{13} \mathrm{C}$ NMR spectroscopy. Thus, the two isomeric dimers, one identical to the isomer obtained by the palladium-catalyzed reaction and the other a different isomer, were produced by the rhodium-catalyzed reaction. Next, several phosphine ligands were examined (Table 1, entries 2-5). To our delight, the use of the dppe ligand suppressed the formation of 2a and the unidentified compounds, and increased the NMR yield of $3 \mathbf{a}$ to $96 \%$ ( $86 \%$ isolated yield, Table 1, entry 4 ). A complex mixture of products was obtained when the reaction temperature was lowered from $130{ }^{\circ} \mathrm{C}$ to $90{ }^{\circ} \mathrm{C}$ (Table 1 , entry 6). Moreover, the use of $[\mathrm{Rh}(\mathrm{OH})(\operatorname{cod})]_{2}$ and $\mathrm{Rh}(\mathrm{acac})(\mathrm{cod})$ as the precatalyst resulted in a decrease of the reaction rate (Table 1, entries 7 and 8 ).

\begin{tabular}{llllll} 
Table 1: Optimization of reaction conditions ${ }^{\mathrm{a}}$. \\
\hline
\end{tabular}

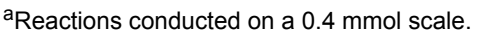

${ }^{b}$ dppm = 1,1-bis(diphenylphosphino)methane, dppe = 1,2-

bis(diphenylphosphino)ethane, dppp $=1,3$ -

bis(diphenylphosphino)propane.

cNMR yield using mesitylene as an internal standard. Isolated yield given in parenthesis.

dUsing $10 \mathrm{~mol} \%$ of $\mathrm{PPh}_{3}$

eUsing $5.0 \mathrm{~mol} \%$ of Rh(acac)(cod).
We propose that the dimerization reaction proceeds through the pathway outlined in Scheme 2. Initially, two molecules of $\mathbf{1 a}$ coordinate to a rhodium(I) center at the terminal carbon-carbon double bonds from their sterically less-hindered sides. Oxidative cyclization occurs in a head-to-head manner to form the five-membered rhodacyclic intermediate $\mathbf{A}$ [22-25], which is in equilibrium with another rhodacyclic intermediate $\mathbf{B}$ via $\sigma-\pi-\sigma$ isomerization. Then, $\beta$-hydride elimination takes place with $\mathbf{B}$ to form rhodium hydride $\mathbf{C}$ stereoselectively. Finally, reductive elimination from $\mathbf{C}$ yields $\mathbf{3 a}$ together with the catalytically active rhodium(I) complex. It is also conceivable, however, that oxidative cyclization of two molecules of 1a occurs in a tail-totail manner to directly furnish $\mathbf{B}$. The other isomer $\mathbf{2 a}$ could be formed through allylic 1,3-migration of rhodium from $\mathbf{C}$ and subsequent reductive elimination.

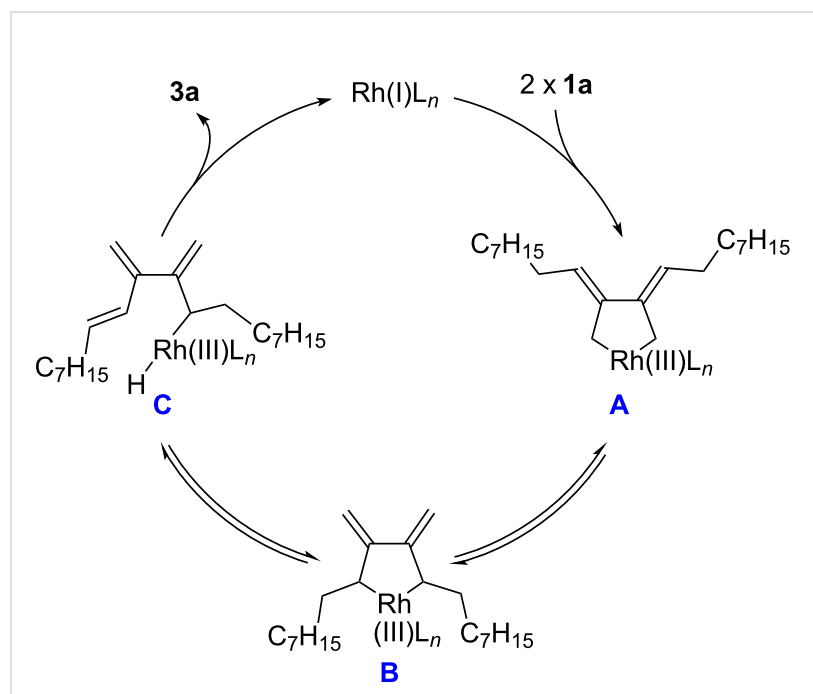

Scheme 2: A proposed reaction pathway.

Under the optimized reaction conditions using dppe as the ligand, various monosubstituted allenes $\mathbf{1 b}-\mathbf{j}$ were subjected to the catalytic dimerization reaction (Table 2). In most cases, essentially one isomer $\mathbf{3}$ was formed, and the other isomer 2 was barely detectable in the ${ }^{1} \mathrm{H}$ NMR spectrum of the crude reaction mixture $(<5 \%)$. Allenes $\mathbf{1 b}-\mathbf{i}$ possessing a primary alkyl group reacted well to afford the corresponding products 3b-i in yields ranging from $63 \%$ to $90 \%$ (Table 2, entries 1-8). Functional groups such as benzyloxy, siloxy, hydroxy and cyano groups were tolerated in the alkyl chain under the reaction conditions. Cyclohexylpropa-1,2-diene (1j) possessing a secondary alkyl group also participated in the dimerization reaction (Table 2, entry 9). On the other hand, 1,1-disubstituted allenes such as 3-methylbuta-1,2-diene and 3-pentylocta-1,2diene failed to undergo the dimerization reaction, in contrast to the nickel-catalyzed reaction $[18,19]$. 
Table 2: Synthesis of cross-conjugated trienes by the allene dimerization reaction ${ }^{\mathrm{a}}$.

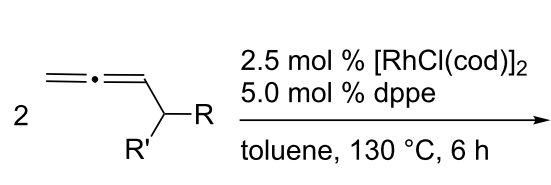

1

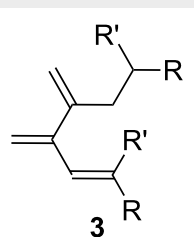

\begin{tabular}{llllll}
\hline Entry & 1 & $\mathrm{R}$ & $\mathrm{R}^{\prime}$ & 3 & $\begin{array}{l}\text { Yield } \\
(\%)^{\mathrm{b}}\end{array}$ \\
\hline
\end{tabular}

\begin{tabular}{llllll}
\hline 1 & $\mathbf{1 b}$ & $\mathrm{C}_{5} \mathrm{H}_{11}$ & $\mathrm{H}$ & $\mathbf{3 b}$ & 85 \\
2 & $\mathbf{1 c}$ & $\mathrm{CH}_{2} \mathrm{Ph}$ & $\mathrm{H}$ & $\mathbf{3 c}$ & $78^{\mathrm{c}}$ \\
3 & $\mathbf{1 d}$ & $\mathrm{Cy}$ & $\mathrm{H}$ & $\mathbf{3 d}$ & $83^{\mathrm{d}}$ \\
4 & $\mathbf{1 e}$ & $\mathrm{CH}_{2} \mathrm{OBn}$ & $\mathrm{H}$ & $\mathbf{3 e}$ & 70 \\
5 & $\mathbf{1 f}$ & $\left(\mathrm{CH}_{2}\right)_{3} \mathrm{OBn}$ & $\mathrm{H}$ & $\mathbf{3 f}$ & 78 \\
6 & $\mathbf{1 g}$ & $\left(\mathrm{CH}_{2}\right)_{3} \mathrm{OSiMe}{ }_{2} t-\mathrm{Bu}$ & $\mathrm{H}$ & $\mathbf{3 g}$ & 90 \\
7 & $\mathbf{1 h}$ & $\left(\mathrm{CH}_{2}\right)_{3} \mathrm{OH}$ & $\mathrm{H}$ & $\mathbf{3 h}$ & 63 \\
8 & $\mathbf{1 i}$ & $\left(\mathrm{CH}_{2}\right)_{3} \mathrm{CN}$ & $\mathrm{H}$ & $\mathbf{3 i}$ & 75 \\
9 & $\mathbf{1 j}$ & $-\left(\mathrm{CH}_{2}\right)_{5}-$ & & $\mathbf{3 j}$ & $60^{\mathrm{d}}$ \\
\hline
\end{tabular}

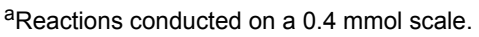

blsolated yield unless otherwise noted.

'The product was accompanied by a small amount of an unidentified impurity.

${ }^{\mathrm{d}}$ NMR yield using mesitylene as an internal standard.

Next, we examined the consecutive double $[4+2]$ cycloaddition reaction of the cross-conjugated trienes obtained in the present study. Triene 3a was treated with 4-phenyl-1,2,4-triazoline-3,5-dione (4, PTAD), a highly reactive dienophile, in toluene at $0{ }^{\circ} \mathrm{C}$ (Scheme 3 ). The conversion of $\mathbf{3 a}$ was complete within $1 \mathrm{~h}$, and after chromatographic isolation, bisadducts $\mathbf{5 a}$ and $\mathbf{5 a}$ ' were obtained in $75 \%$ and $6 \%$ yields, respectively. The major bisadduct 5a resulted from initial addition to the more congested diene moiety of $\mathbf{3 a}$ (site $\beta$ ). When tetracyanoethylene (6, TCNE), which was a less reactive dienophile than $\mathbf{4}$, was used, [4+2] cycloaddition also occurred preferentially at site $\beta$, but only once on heating at $60{ }^{\circ} \mathrm{C}$ for $24 \mathrm{~h}$.

\section{Conclusion}

In summary, we have developed a new dimerization reaction of monosubstituted allenes catalyzed by a rhodium(I)/dppe complex, allowing the stereoselective formation of substituted cross-conjugated trienes. It is interesting that the rhodium catalyst and the palladium catalyst gave different types of crossconjugated trienes.

\section{Experimental General procedure for rhodium-catalyzed dimerization of monosubstituted allenes}

To a side-arm tube equipped with a stirrer bar, was added $[\mathrm{RhCl}(\mathrm{cod})]_{2}(4.9 \mathrm{mg}, 2.5 \mathrm{~mol} \%)$ and dppe (7.7 mg, $\left.5 \mathrm{~mol} \%\right)$. The tube was evacuated and refilled with argon three times. Then, toluene $(4 \mathrm{~mL})$ and substrate $1(0.4 \mathrm{mmol})$ were added via syringe and the tube was closed. After heating at $130{ }^{\circ} \mathrm{C}$ for $6 \mathrm{~h}$, the reaction mixture was cooled to room temperature, passed through a pad of Florisil ${ }^{\circledR}$ and eluted with ethyl acetate $(\approx 90-100 \mathrm{~mL})$. The filtrate was concentrated under reduced pressure and the residue purified by preparative thin-layer chromatography to give product $\mathbf{3}$. Although the isolated $\mathbf{3}$ was relatively labile, it could be kept at $-30{ }^{\circ} \mathrm{C}$ for days without any detectable decomposition or polymerization.

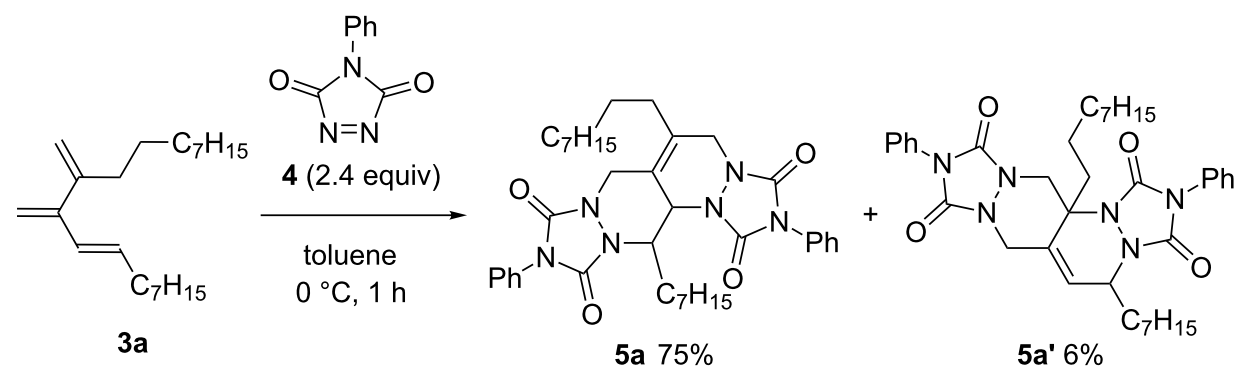

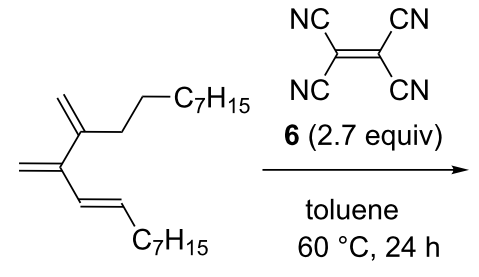

$3 a$

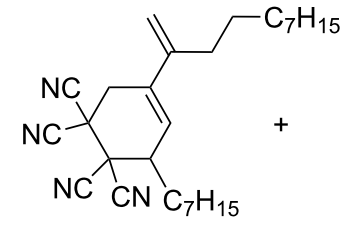

7a $62 \%$<smiles>C/C=C/C=C1/CC(C#N)(C#N)C(C#N)(C#N)CC1=CCCC</smiles>

7a' $19 \%$ 


\section{Supporting Information}

\section{Supporting Information File 1}

Experimental details and spectroscopic data for new compounds.

[http://www.beilstein-journals.org/bjoc/content/ supplementary/1860-5397-7-67-S1.pdf]

\section{Acknowledgements}

This work was supported in part by MEXT (Grant-in-Aid for Challenging Exploratory Research, No. 21656033). T. T. is grateful for Research Fellowship from JSPS for Young Scientists.

\section{References}

1. Hopf, H. Nature 2009, 460, 183-184. doi:10.1038/460183a

2. Tsuge, O.; Wada, E.; Kanemasa, S. Chem. Lett. 1983, 12, 239-242. doi:10.1246/cl.1983.239

3. Kwon, O.; Park, S. B.; Schreiber, S. L. J. Am. Chem. Soc. 2002, 124, 13402-13404. doi:10.1021/ja028086e

4. Brummond, K. M.; You, L. Tetrahedron 2005, 61, 6180-6185. doi:10.1016/j.tet.2005.03.141

5. Bradford, T. A.; Payne, A. D.; Willis, A. C.; Paddon-Row, M. N.; Sherburn, M. S. J. Org. Chem. 2010, 75, 491-494. doi:10.1021/j09024557

6. Woo, S.; Squires, N.; Fallis, A. G. Org. Lett. 1999, 1, 573-576. doi:10.1021/ol990695c

7. Chang, H.-M.; Cheng, C.-H. J. Org. Chem. 2000, 65, 1767-1773. doi:10.1021/jo991651k

8. Brummond, K. M.; Chen, H.; Sill, P.; You, L. J. Am. Chem. Soc. 2002, 124, 15186-15187. doi:10.1021/ja027588p

9. Chin, C. S.; Lee, H.; Park, H.; Kim, M. Organometallics 2002, 21, 3889-3896. doi:10.1021/om020410r

10. Kang, B.; Kim, D.-H.; Do, Y.; Chang, S. Org. Lett. 2003, 5, 3041-3043. doi:10.1021/ol035014z

11. Shi, M.; Shao, L.-X. Synlett 2004, 807-810. doi:10.1055/s-2004-820017

12. Bräse, S.; Wertal, H.; Frank, D.; Vidović, D.; de Meijere, A. Eur. J. Org. Chem. 2005, 4167-4178. doi:10.1002/ejoc.200500330

13. Bradford, T. A.; Payne, A. D.; Willis, A. C.; Paddon-Row, M. N.; Sherburn, M. S. Org. Lett. 2007, 9, 4861-4864. doi:10.1021/ol7021998

14. Miller, N. A.; Willis, A. C.; Paddon-Row, M. N.; Sherburn, M. S. Angew. Chem., Int. Ed. 2007, 46, 937-940. doi:10.1002/anie.200603335

15. Shimp, H. L.; Hare, A.; McLaughlin, M.; Micalizio, G. C. Tetrahedron 2008, 64, 3437-3445. doi:10.1016/j.tet.2008.02.015

16. Kim, S.; Seomoon, D.; Lee, P. H. Chem. Commun. 2009, 1873-1875. doi:10.1039/b823037d

17. Beydoun, K.; Zhang, H.-J.; Sundararaju, B.; Demerseman, B.; Achard, M.; Xi, Z.; Bruneau, C. Chem. Commun. 2009, 6580-6582. doi:10.1039/b913595b

18. Englert, M.; Jolly, P. W.; Wilke, G. Angew. Chem., Int. Ed. Engl. 1972, 11, 136-137. doi:10.1002/anie.197201361

19. Pasto, D. J.; Huang, N.-Z. Organometallics 1985, 4, 1386-1395. doi:10.1021/om00127a014
20. Pasto, D. J.; Huang, N.-Z.; Eigenbrot, C. W. J. Am. Chem. Soc. 1985, 107, 3160-3172. doi:10.1021/ja00297a022

21. Arisawa, M.; Sugihara, T.; Yamaguchi, M. Chem. Commun. 1998, 2615-2616. doi:10.1039/a807527a

22. Osakada, K.; Choi, J.-C.; Sarai, S.; Koizumi, T.; Yamamoto, T. Chem. Commun. 1997, 1313-1314. doi:10.1039/a701859b

23. Lu, P.; Ma, S. Org. Lett. 2007, 9, 2095-2097. doi:10.1021/ol070632r

24. Park, J. H.; Kim, E.; Kim, H.-M.; Choi, S. Y.; Chung, Y. K. Chem. Commun. 2008, 2388-2390. doi:10.1039/b718107h

25. Kawamura, T.; Inagaki, F.; Narita, S.; Takahashi, Y.; Hirata, S.; Kitagaki, S.; Mukai, C. Chem.-Eur. J. 2010, 16, 5173-5183. doi:10.1002/chem.200903568

\section{License and Terms}

This is an Open Access article under the terms of the Creative Commons Attribution License

(http://creativecommons.org/licenses/by/2.0), which permits unrestricted use, distribution, and reproduction in any medium, provided the original work is properly cited.

The license is subject to the Beilstein Journal of Organic Chemistry terms and conditions:

(http://www.beilstein-journals.org/bjoc)

The definitive version of this article is the electronic one which can be found at: doi:10.3762/bjoc. 7.67 